\title{
Absence of Glial Fibrillary Acidic Protein and Vimentin Prevents Hypertrophy of Astrocytic Processes and Improves Post-Traumatic Regeneration
}

\author{
Ulrika Wilhelmsson, ${ }^{1}$ Lizhen Li, ${ }^{1}$ Marcela Pekna, ${ }^{1}$ Claes-Henric Berthold, ${ }^{2}$ Sofia Blom, ${ }^{1}$ Camilla Eliasson, ${ }^{1}$ \\ Oliver Renner, ${ }^{5}$ Eric Bushong, ${ }^{4}$ Mark Ellisman, ${ }^{4}$ Todd E. Morgan, ${ }^{3}$ and Milos Pekny ${ }^{1}$ \\ ${ }^{1}$ Department of Medical Biochemistry and ${ }^{2}$ Department of Anatomy and Cell Biology, Sahlgrenska Academy at Göteborg University, SE-405 30 Göteborg, \\ Sweden, ${ }^{3}$ Andrus Gerontology Center, University of Southern California, Los Angeles, California 90089-0191, ${ }^{4}$ National Center for Microscopy and Imaging \\ Research, University of California, San Diego, La Jolla, California 92093-0608, and ${ }^{5}$ Spanish National Cancer Centre, E-28029 Madrid, Spain
}

\begin{abstract}
The regenerative capacity of the CNS is extremely limited. The reason for this is unclear, but glial cell involvement has been suspected, and oligodendrocytes have been implicated as inhibitors of neuroregeneration (Chen et al., 2000, GrandPre et al., 2000; Fournier et al., 2001). The role of astrocytes in this process was proposed but remains incompletely understood (Silver and Miller, 2004). Astrocyte activation (reactive gliosis) accompanies neurotrauma, stroke, neurodegenerative diseases, or tumors. Two prominent hallmarks of reactive gliosis are hypertrophy of astrocytic processes and upregulation of intermediate filaments. Using the entorhinal cortex lesion model in mice, we found that reactive astrocytes devoid of the intermediate filament proteins glial fibrillary acidic protein and vimentin $\left(\mathrm{GFAP}^{-/-} \mathrm{Vim}^{-/-}\right)$, and consequently lacking intermediate filaments (Colucci-Guyon et al., 1994; Pekny et al., 1995; Eliasson et al., 1999), showed only a limited hypertrophy of cell processes. Instead, many processes were shorter and not straight, albeit the volume of neuropil reached by a single astrocyte was the same as in wild-type mice. This was accompanied by remarkable synaptic regeneration in the hippocampus. On a molecular level, GFAP ${ }^{-1-} \mathrm{Vim}^{-/}$reactive astrocytes could not upregulate endothelin B receptors, suggesting that the upregulation is intermediate filament dependent. These findings show a novel role for intermediate filaments in astrocytes and implicate reactive astrocytes as potent inhibitors of neuroregeneration.
\end{abstract}

Key words: GFAP; vimentin; intermediate filaments; astrocytes; regeneration; hippocampus; endothelin B receptor

\section{Introduction}

Astrocytes are of major importance for normal functioning of the CNS, but the role of reactive astrocytes in neuroprotection or in healing and recovery in various CNS pathologies remains mostly unclear. Reactive astrocytes may act as a barrier, inhibiting neuroregeneration and neurite outgrowth (Silver and Miller, 2004). Alternatively, they may provide a permissive substrate for axonal regrowth (Ridet et al., 1997) or facilitate the integration of transplanted neural stem cells (Nishida et al., 2000). Studies of reactive astrocytes have been hampered by the difficulty of selectively affecting astrocytes in experimental models in vivo (Delaney et al., 1996; Bush et al., 1999). Upregulation of intermediate filaments is a hallmark of reactive astrocytes, and the generation of mice lacking intermediate filament proteins in astrocytes has made it possible to address the role of reactive astrocytes in vivo

Received Sept. 18, 2003; revised April 8, 2004; accepted April 14, 2004.

This study was supported by grants from the Swedish Research Council (11548), Swedish Cancer Foundation (3622), Swedish Society for Medicine, Swedish Society for Medical Research, King Gustaf V Foundation, Volvo Assar Gabrielsson Fond, Swedish Stroke Foundation (to M. P.), National Institutes of Health-National Center for Research Resources Program Grant P41 RR04050 (to M.E.), and by an Alzheimer's Association Faculty Scholar Award (to T.M.). We thank Dr. Diana Price for valuable input into the dye-filling experiments.

Correspondence should be addressed to Dr. Milos Pekny, Department of Medical Biochemistry, Sahlgrenska Academy at Göteborg University, Box 440, SE-405 30 Göteborg, Sweden. E-mail: Milos.Pekny@medkem.gu.se. DOI:10.1523/JNEUROSCI.0820-04.2004

Copyright $\odot 2004$ Society for Neuroscience $\quad$ 0270-6474/04/245016-06\$15.00/0
(Pekny, 2001). We have shown that reactive astrocytes in mice deficient in the intermediate filament proteins glial fibrillary acidic protein (GFAP) and vimentin (Vim; GFAP ${ }^{-/-} \mathrm{Vim}^{-/-}$) are completely devoid of intermediate filaments (Eliasson et al., 1999), and that glial scarring after brain or spinal cord trauma in these mice is less organized (Pekny et al., 1999). We proposed that upregulation of astrocytic intermediate filaments is a crucial step in astrocyte activation (Pekny et al., 1999).

Here, we address the role of reactive astrocytes in CNS regeneration after unilateral entorhinal cortex lesioning (Matthews et al., 1976; Caceres and Steward, 1983; Steward and Vinsant, 1983). Entorhinal cortex lesion interrupts axonal connections (perforant path) between the entorhinal cortex and projection area in the outer molecular layer of the dentate gyrus of the hippocampus, where degenerating neurons trigger reactive gliosis. The distance between these two regions allows assessment of both the response of astrocytes and regeneration in the hippocampus, which is not directly affected by the lesion.

We found that in lesioned $G F A P^{-1-} \mathrm{Vim}^{-1-}$ mice, activated astrocytes in the molecular layer of the hippocampus exhibited fewer long and straight processes. This was accompanied by prominent synaptic regeneration and resulted in a complete restoration of lost synaptic complexes in the outer molecular layer of the dentate gyrus of the hippocampus by day 14 . Thus, although intermediate filaments are not required for the formation of as- 



Figure 1. The absence of astrocytic intermediate filaments in $\mathrm{GFAP}^{-/-} \mathrm{Vim}^{-/-}$mice prevents hypertrophy of astrocytic processes during astrocyte activation. $a$, Intracellular presence of glutamine synthase is astrocyte specific and colocalizes with GFAP. Green, Glutamine synthase; red, GFAP; blue, cell nuclei visualized by T0-PRO-3. Scale bar, $20 \mu \mathrm{m}$. b, c, Before entorhinal cortex lesion, $\mathrm{GFAP}^{-/-} \mathrm{Vim}^{-/-}$(GV) and wild-type (WT) mice exhibited similar astrocyte morphology and length of astrocytic processes. $d$, By day 4 , after entorhinal cortex lesion, WT astrocytes are reactive and display hypertrophic astrocytic processes. $e$, In contrast, the astrocytic processes in GV mice are not hypertrophic. Green, Glutamine synthase; red, cell nuclei visualized by propidium iodide. Scale bar, $20 \mu \mathrm{m}$. The length of astrocytic processes $4 \mathrm{~d}$ after entorhinal cortex lesion is 53 or $46 \%$ shorter in GV than WT mice (visualized by glutamine synthase antibodies, $f$, ${ }^{* * *} p<0.0001$, and S100 antibodies, $g$, ${ }^{* * *} p<0.001$, respectively). This phenomenon persists at day 14 after the entorhinal cortex lesion visualized by glutamine synthase antibodies ( $f$; $\left.{ }^{* * * *} p<0.0001\right)$. Reactive astrocytes deficient in either GFAP (G) or vimentin (V) exhibit an intermediate phenotype at day 4 ( $f$; ${ }^{* *} p<0.01$ and $^{*} p<0.05$, respectively).

trocytic processes during development, they are of fundamental importance for reactive astrocytes.

\section{Materials and Methods}

Mice. Mice carrying a null mutation in the GFAP and/or vimentin gene and the wild-type controls have been described previously (ColucciGuyon et al., 1994; Pekny et al., 1995, 1999). All mice were on a C57BL/ $6-129 \mathrm{~Sv}-129$ Ola genetic background, were $>5$ months old, and were maintained in a barrier animal facility.

Cell cultures. Primary cultures enriched in reactive astrocytes were prepared from 2-d-old mice (five GFAP ${ }^{-/-} \mathrm{Vim}^{-/-}$and five wild type) (Pekny et al., 1998). Before enzyme-linked immunosorbent assays, the cultures were grown for $10 \mathrm{~d}$ in 96-well plates (Greiner Bio-One, Frickenhausen, Germany) containing DMEM (D5671; Sigma-Aldrich, St Louis, MO), 10\% fetal calf serum (Invitrogen, Paisly, UK), 2 mм L-glutamine, and penicillin-streptomycin (Invitrogen).

ELISA for glutamine synthase quantification. Cells grown in 96-well plates were fixed with ice-cold methanol at $-20^{\circ} \mathrm{C}$ for $15 \mathrm{~min}$. Endogenous peroxidase activity was blocked with $0.3 \% \mathrm{H}_{2} \mathrm{O}_{2}$ for $30 \mathrm{~min}$ at room temperature. The plates were saturated with PBS containing $5 \%$ bovine serum albumin (BSA) (Sigma-Aldrich) for $30 \mathrm{~min}$ at room temperature. The cells were then incubated with mouse monoclonal anti-glutamine synthase antibody $(\mathrm{Ab})$ (Chemicon, Temecula, $\mathrm{CA}$ ) for $60 \mathrm{~min}$ at room temperature, washed with PBS, and incubated with horseradish peroxidase-conjugated polyclonal anti-mouse IgG Ab (Dako, Glostrup, Denmark) for $60 \mathrm{~min}$ at room temperature. The enzyme reaction was started by the adding of color reagent [20 mg of 1,2-phenylendiamine-dihydrochloride (Sigma-Aldrich) and $10 \mu \mathrm{l}$ of $\mathrm{H}_{2} \mathrm{O}_{2}$ in $75 \mathrm{ml}$ of $0.1 \mathrm{M}$ citrate-phosphate buffer, $\mathrm{pH}$ 5]. The reaction was stopped by adding $1 \mathrm{M} \mathrm{H}_{2} \mathrm{SO}_{4}$ after 4 min. The staining was quantified spectrophotometrically at $490 \mathrm{~nm}$.

Surgery. Unilateral entorhinal cortex lesion was performed as described previously (Stone et al., 1998). After 4 or $14 \mathrm{~d}$, the mice were perfused transcardially with $4 \%$ paraformaldehyde (for immunohisto- chemistry) or $3 \%$ glutaraldehyde and $2 \%$ paraformaldehyde (for electron microscopy).

Evaluation of astrocytic processes by immunohistochemistry. Brains were fixed for $1 \mathrm{~d}$ at $4^{\circ} \mathrm{C}$ in paraformaldehyde and immersed in $30 \%$ sucrose and $0.05 \mathrm{~m}$ sodium phosphate, $\mathrm{pH} 7.3$, for $3 \mathrm{~d}$ at $4^{\circ} \mathrm{C}$. Horizontal cryosections $(25 \mu \mathrm{m})$ were made covering the same area of hippocampus as analyzed by electron microscopy (see below) and stored in a cryoprotectant (50\% 0.05 M sodium phosphate, $\mathrm{pH} 7.3,30 \%$ ethylene glycol, $20 \%$ glycerol) at $-20^{\circ} \mathrm{C}$. After several washes in PBS, the sections were incubated in $0.05 \%$ glycine in PBS for $1 \mathrm{hr}$ at room temperature and permeabilized overnight in PBS containing $0.5 \%$ Tween 20 and $1 \%$ BSA at $4^{\circ} \mathrm{C}$. Next, the sections were incubated with monoclonal $\mathrm{Ab}$ against glutamine synthase (Chemicon; 1:100) or rabbit anti-cow S100 (Dako; $1: 200$ ) in $0.01 \%$ Tween 20 and $1 \%$ BSA in PBS overnight. The following day, goat antimouse antibodies conjugated with Alexa 488 (Molecular Probes, Eugene, OR; 1:500) or goat anti-rabbit antibodies conjugated with Alexa 568 (Molecular Probes; 1:500) were incubated with the sections overnight at $4^{\circ} \mathrm{C}$. For nuclear staining, propidium iodide (Sigma-Aldrich) was added to the last wash before mounting. Astrocytes and their processes were quantified on superimposed pictures of nine serial confocal images covering a thickness of $8 \mu \mathrm{m}$ (glutamine synthase detection) or four serial confocal images covering a thickness of $3 \mu \mathrm{m}$ (S100 detection) obtained with a laser-scanning confocal microscope (TCS NT; Leica, Heidelberg, Germany) and a $40 \times$ objective. We selected astrocytes with clearly visible cell nuclei and soma. The lengths of the longest cellular processes of 20 such astrocytes in the molecular layer in the dentate gyrus of the hippocampus in each mouse were measured. At day 4 after entorhinal cortex lesion, the number of mice examined using glutamine synthase immunostaining was six wild type, five $G F A P^{-/-}$, two $\mathrm{Vim}^{-1-}$, and five $\mathrm{GFAP}^{-1-} \mathrm{Vim}^{-1-}$; at day 14, eight wild type, four $\mathrm{GFAP}^{-/-}$, four $\mathrm{Vim}^{-/-}$, and six $\mathrm{GFAP}^{-/-} \mathrm{Vim}^{-/-}$were examined. Six wildtype and five GFAP ${ }^{-1-}$ Vim $^{-1-}$ mice were examined using S100 immunostaining at both day 4 and 14 .

Dye filling of astrocytes. Intracellular injection of astrocytes in lightly fixed tissue slices was performed as described previously (Bushong et al., $2002,2003)$. On day 4 after entorhinal cortex lesion, the mice were transcardially perfused with oxygenated Ringer's solution $(0.79 \% \mathrm{NaCl}$, $0.038 \% \mathrm{KCl}, 0.02 \% \mathrm{MgCl}_{2} \cdot 6 \mathrm{H}_{2} \mathrm{O}, 0.018 \% \mathrm{Na}_{2} \mathrm{HPO}_{4}, 0.125 \% \mathrm{NaHCO}_{3}$, $0.03 \% \mathrm{CaCl}_{2} \cdot 2 \mathrm{H}_{2} \mathrm{O}, 0.2 \%$ dextrose, $0.02 \%$ xylocaine), followed by $4 \%$ paraformaldehyde in PBS, $\mathrm{pH} 7.4$, for $8-10 \mathrm{~min}$, both at $37^{\circ} \mathrm{C}$. The brain was placed in ice-cold PBS and cut with a vibratome into $75 \mu \mathrm{m}$ horizontal slices. The slices were stored in PBS at $4^{\circ} \mathrm{C}$ and examined with an Olympus BX50WI microscope using infrared-differential interference contrast optics [Olympus, Melville, NY; $60 \times$ water objective numerical aperture (NA) 1.4]. Astrocytes in the medial outer molecular layer of the dentate gyrus of the hippocampus were identified by the shape and size of their somata. Glass micropipettes (outer diameter, $1.00 \mathrm{~mm}$; inner diameter, $0.58 \mathrm{~mm}$ ) were pulled on a vertical puller (David Kopf Instruments, Tujunga, CA) and backfilled with 5\% aqueous lucifer yellow (SigmaAldrich). Astrocytes were impaled and iontophoretically injected with the dye using $1 \mathrm{sec}$ pulses of negative current $(0.5 \mathrm{~Hz})$ for $1-2 \mathrm{~min}$. After several cells were filled, the slices were placed in ice-cold $4 \%$ paraformaldehyde for at least $1 \mathrm{hr}$. For immunolabeling of GFAP in the dye-filled astrocytes, the slices were repeatedly washed in PBS and permeabilized for $1 \mathrm{hr}$ at room temperature in PBS containing 1\% BSA, 0.25\% Triton $\mathrm{X}-100$, and $3 \%$ normal donkey serum followed by incubation with guinea pig antibodies against GFAP (Sigma-Aldrich; 1:100) for $48 \mathrm{hr}$ at 
$4^{\circ} \mathrm{C}$ in PBS containing $1 \%$ BSA, $0.1 \%$ Triton $\mathrm{X}-100$, and $0.3 \%$ normal donkey serum. After washing several times in PBS, donkey antiguinea pig antibodies conjugated with Rhodamine Red-X (Jackson ImmunoResearch, West Grove, PA; 1:300) was added to the slices, incubated overnight at $4^{\circ} \mathrm{C}$, and then mounted in gelvatol (Harlow and Lane, 1988). The slices were examined using a Radiance2000 laserscanning confocal system (Bio-Rad, Hercules, CA) attached to a Nikon E600FN microscope (Kanagawa, Tokyo, Japan) with a $60 \times$ oil immersion objective (NA 1.4). Image visualization and analysis were performed using Imaris 3.3 (Bitplane, Zurich, Switzerland) and ImageJ (National Institutes of Health, Bethesda, MD) software. Quantification of neuropil volume reached by a dye-filled astrocyte was performed on three-dimensional reconstructed cells (see Fig. $2 c$ ) in three wild-type and three $G F A P^{-/-}$ $\mathrm{Vim}^{-1-}$ mice (total of 57 cells quantified) using Imaris 3.3 software. The number and character of cell processes reaching outside a $40 \mu \mathrm{m}$ wide circle centered around the soma was assessed by using ImageJ software on superimposed serial images in 61 dye-filled astrocytes.

Immunodetection of endothelin $B$ receptors. Perfused brains were postfixed for one day at $4^{\circ} \mathrm{C}$ in paraformaldehyde, and horizontal vibratome sections $(50 \mu \mathrm{m})$ were made covering the same area of the hippocampus as analyzed by electron microscopy and by immunohistochemical staining (see above). Rabbit anti-endothelin $\mathrm{B}$ receptor $\mathrm{Ab}$ (Alomone Labs, Jerusalem, Israel) and mouse anti-GFAP Ab (clone GA5; Sigma-Aldrich), both diluted 1:100, followed by Alexa 488-conjugated anti-rabbit and Alexa 568-conjugated anti-mouse antibodies (Molecular Probes), both diluted 1:500, were used for immunohistochemical staining. The sections were processed as described above (see Quantification of Astrocytic Processes). For nuclear staining, propidium iodide (Sigma-Aldrich) or TO PRO-3 (Molecular Probes) was added to the last wash before mounting.

Electron microscopy. The fixed brains were sectioned horizontally with a vibratome. Five $200 \mu \mathrm{m}$ thick sections (labeled S1-S5) were collected, starting $1500 \mu \mathrm{m}$ below the top border of the hippocampus. The left and right hippocampal regions were trimmed from each of the five sections, postfixed with $1 \%$ osmiumtetroxide for $2 \mathrm{hr}$ at $6^{\circ} \mathrm{C}$, dehydrated in acetone, and embedded in Vestopal W (Fluka, Chemie, Liechtenstein). Series of semithin $(0.5-1 \mu \mathrm{m}$ thick) and ultra-thin $(60-80 \mathrm{~nm}$ thick) sections were cut on an LKB Ultratome (LKB-Wallac, Gaithersburg, MD) from S2 or S3. Semithin sections were mounted on glass slides and stained as described previously (Richardson et al., 1969). The part of the dentate gyrus containing the molecular layer and granular layer was cut into ultra-thin sections, stained with uranyl acetate and lead citrate, and examined in a Philips 400 electron microscope (Berthold et al., 1982). An area from the outer part of the molecular layer, $\sim 900 \mu \mathrm{m}^{2}(45 \times 20 \mu \mathrm{m})$, was photographed at $10,000 \times$ magnification, and synaptic complexes were quantified. Synaptic
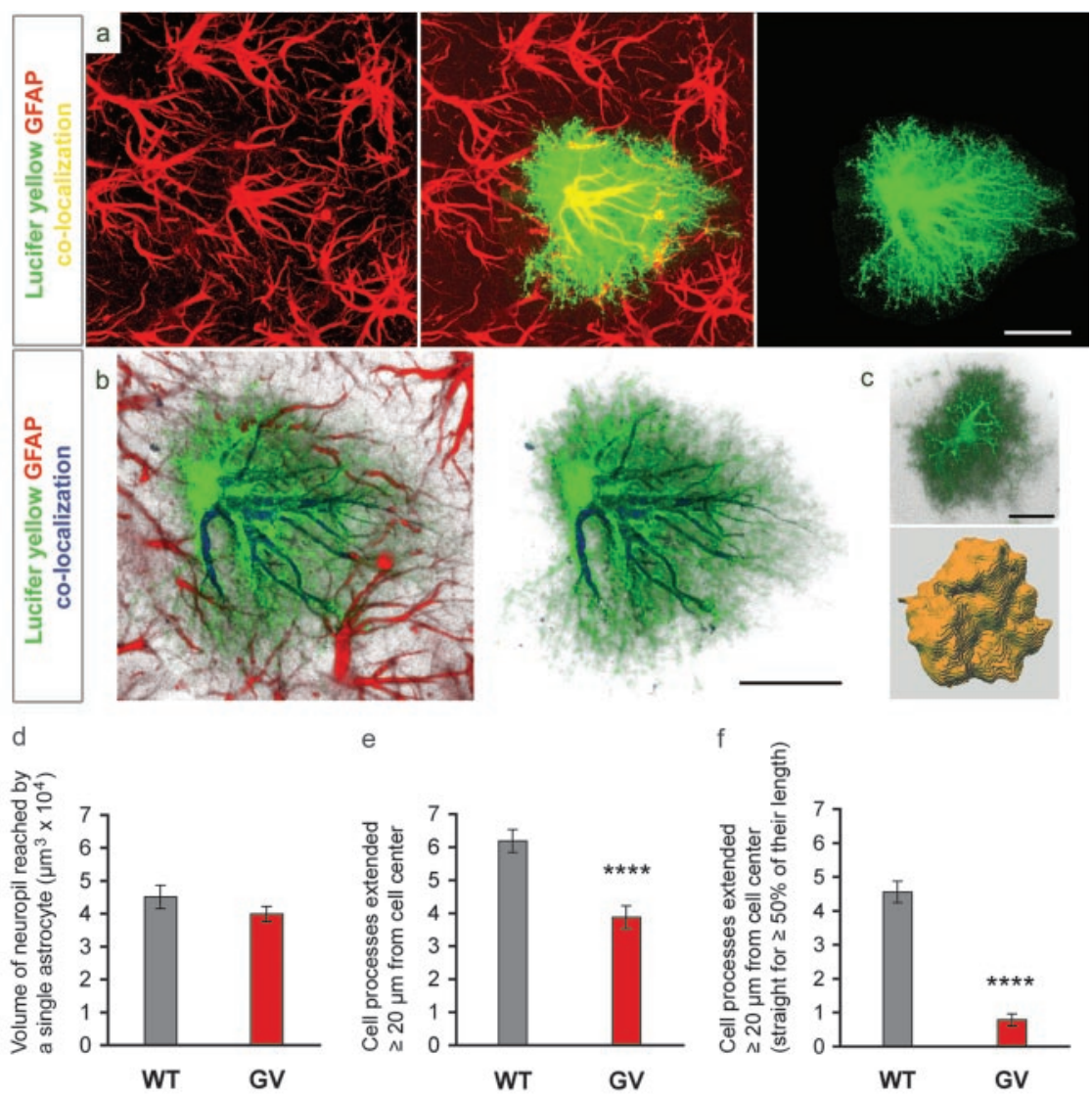

e
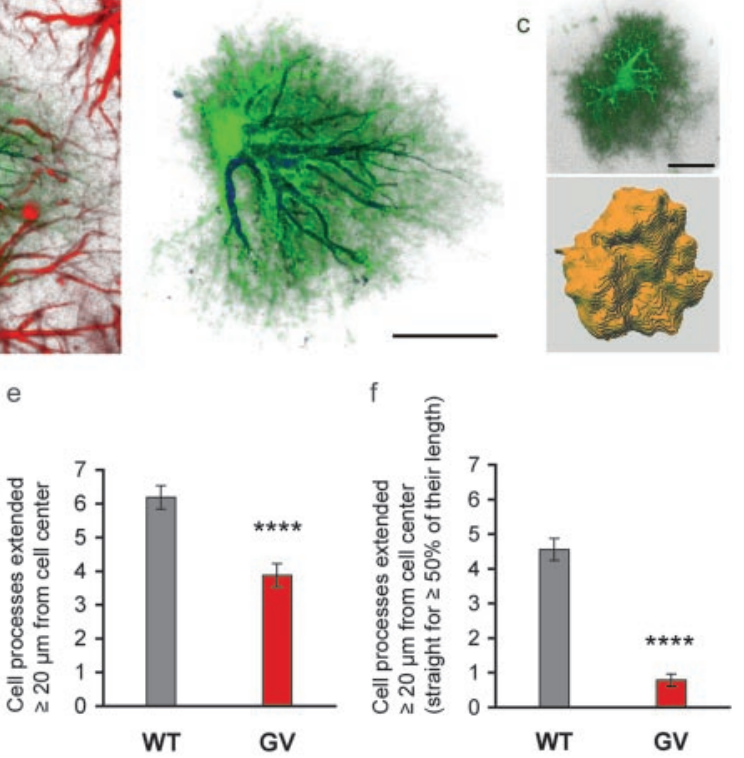

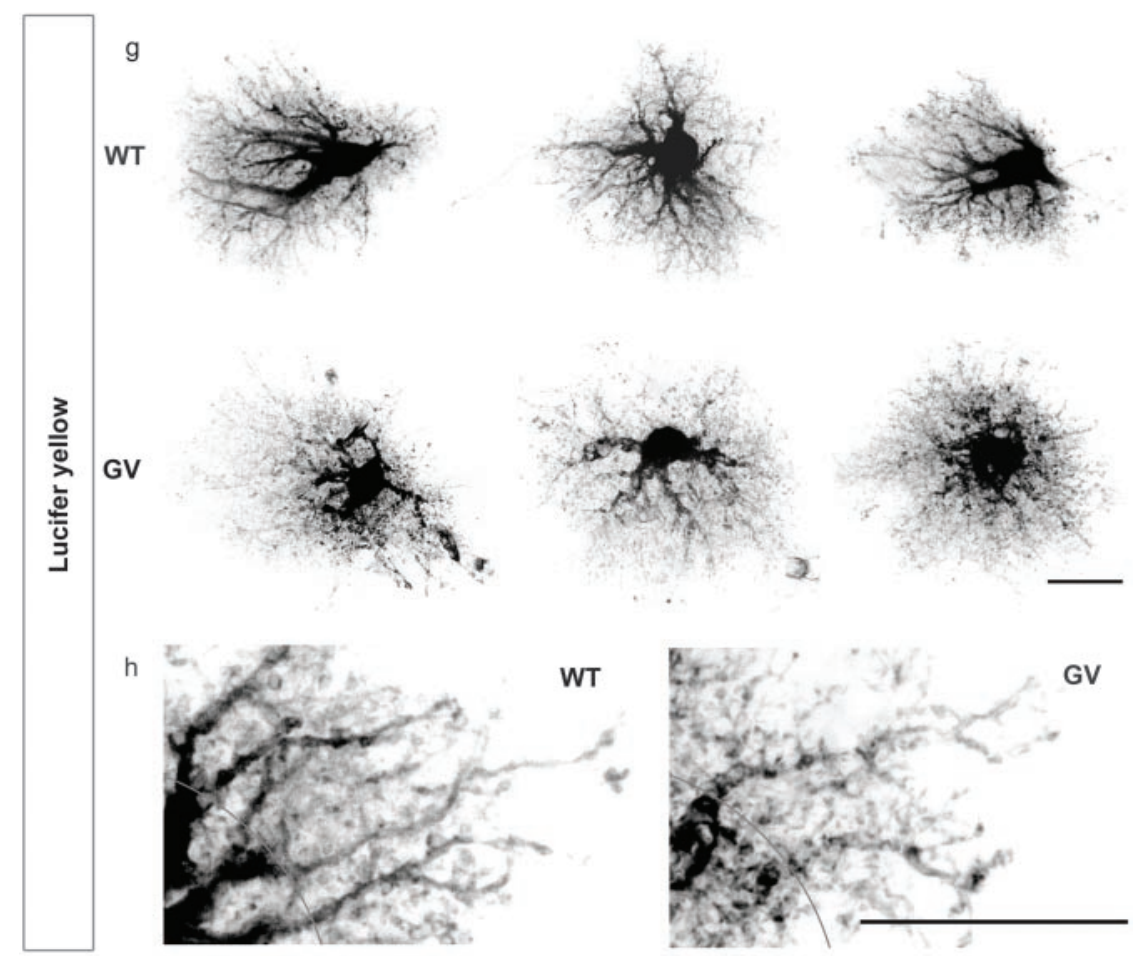

Figure 2. Dye filling reveals an altered morphology of astrocytic processes in GFAP $P^{-1-} \operatorname{Vim}^{-1-}(\mathrm{GV})$ reactive astrocytes. $a$, Filling of individual reactive astrocytes with lucifer yellow shows many fine cellular processes that are not visualized by GFAP antibodies. $a, b$, GFAP-containing intermediate filaments are abundant in the main astrocytic processes but not detectable in many fine and terminal processes. Green, Lucifer yellow; red, GFAP. $c, d$, Three-dimensional reconstruction ( $c$ ) showed that $\mathrm{GFAP}^{-1-} \mathrm{Vim}^{-1-}$ and wild-type (WT) reactive astrocytes reach comparable volume of brain tissue at $4 \mathrm{~d}$ after entorhinal cortex lesion $(d)$, but their processes are less hypertrophic; GFAP ${ }^{-/-} \mathrm{Vim}^{-1-}$ astrocytes compared with wild-type have fewer long processes $\left(e^{* * * *} p<0.0001 ; g, h\right)$ as well as fewer straight processes $\left(f{ }^{* * * *} p<0.0001 ; g, h\right)$. Black, Lucifer yellow. A distance of $20 \mu \mathrm{m}$ from the center of the soma is indicated in $h$. Scale bars, $20 \mu \mathrm{m}$. 
complexes were defined as structures that met two criteria: (1) restricted zone of two membranes in apposition, one or both exhibiting increased thickness or electron contrast, and (2) presence of vesicles, $30-50 \mathrm{~nm}$ in size, in one or both of the two cytoplasmic domains separated by the opposing membranes.

Statistical analysis. All analyses were performed as blind experiments. Data are presented as means \pm SEM. Statistical analysis of the data was performed using a two-tailed $t$ test.

\section{Results}

Astrocytes in the molecular layer of the dentate gyrus of the hippocampus were visualized by immunodetection of glutamine synthase. To confirm the astrocyte specificity of the antibodies, we costained reactive astrocytes in the molecular layer of the dentate gyrus of the hippocampus of wild-type mice with GFAP antibodies (Fig. 1a). No difference in glutamine synthase levels between primary cultures of wild-type and $\mathrm{GFAP}^{-/-} \mathrm{Vim}^{-/-}$reactive astrocytes was shown by ELISA (optical density, $0.71 \pm$ 0.02 and $0.73 \pm 0.01$, respectively), and glutamine synthase was distributed homogenously in both types of cells (Fig. 1b,c). Thus, antibodies against glutamine synthase could be used to evaluate the morphological appearance of astrocytes.

The degree of hypertrophy of astrocytic processes was assessed by measuring the longest process in astrocytes in the molecular layer of the dentate gyrus of the hippocampus. On the side contralateral to entorhinal cortex lesion, the length of astrocytic processes was similar in wild-type and GFAP ${ }^{-/-} \mathrm{Vim}^{-/-}$mice $(12.6 \pm 0.6$ vs $12.0 \pm 0.9 \mu \mathrm{m}$ ) (Fig. $1 b, c)$. On the lesioned side, however, reactive astrocytes in the molecular layer showed more prominent signs of hypertrophy in wild-type mice with glutamine synthase-positive processes longer than in $G F A P^{-/-}$ Vim $^{-/-}$mice (Fig. 1d,e) at both $4 \mathrm{~d}$ after entorhinal cortex lesion $(17.1 \pm 1.1$ vs $8.1 \pm 0.5 \mu \mathrm{m} ; p<0.0001)$ (Fig. $1 f)$ and at $14 \mathrm{~d}$ $(11.8 \pm 0.6$ vs $8.2 \pm 0.5 \mu \mathrm{m} ; p<0.0001)$ (Fig. $1 f)$. The length of processes of reactive astrocytes in $G F A P^{-/-}$and in $\mathrm{Vim}^{-/-}$mice at $4 \mathrm{~d}$ after lesion was shorter than in wild-type mice but longer than in GFAP $^{-/-}$Vim $^{-/-}$mice $(14.1 \pm 0.7$ and $14.9 \pm 0.1 \mu \mathrm{m}$, respectively) (Fig. $1 f$ ). In the next experiment, we evaluated the morphological appearance of reactive astrocytes by using antibodies against another astrocytic marker, S100. Again, significantly longer processes were found in wild type compared with $\mathrm{GFAP}^{-/-} \mathrm{Vim}^{-/-}$reactive astrocytes at $4 \mathrm{~d}$ after entorhinal cortex lesion $(19.7 \pm 1.0$ vs $10.7 \pm 1.0 \mu \mathrm{m} ; p<0.001)$ (Fig. $1 g$ ), and this trend was present also at $14 \mathrm{~d}(18.5 \pm 2.2 \mathrm{vs} 14.0 \pm 0.5 \mu \mathrm{m} ; p=$ 0.11) (Fig. $1 \mathrm{~g}$ ). Thus, the degree of hypertrophy of astrocytic processes was significantly altered in the absence of intermediate filaments.

To further evaluate the effect of the absence of intermediate filaments on hypertrophy of cellular processes of reactive astrocytes and to determine whether this has an impact on the volume of tissue they access, we performed dye-filling experiments that allowed three-dimensional reconstruction of astrocytes in situ (Bushong et al., 2002). Consistent with previously published data (Bushong et al., 2002; Ogata and Kosaka, 2002), the dye filling reveals the true action radius of individual astrocytes (Fig. 2a). Apart from the main astrocytic processes, which can be visualized by antibodies against GFAP or glutamine synthase, dye filling also reveals terminal processes, and this gives astrocytes a characteristic bushy appearance (Fig. $2 a, b$ ). We found no difference in the volume of tissue accessed by wild-type and GFAP ${ }^{-/-} \mathrm{Vim}^{-/-}$reactive astrocytes in the molecular layer of the dentate gyrus of the hippocampus on the lesioned side $\left(4.51 \times 10^{4} \pm 0.35 \times 10^{4}\right.$ vs $4.00 \times 10^{4} \pm 0.23 \times 10^{4} \mu^{3}$ ) (Fig. $2 d$ ); however, the appearance of $\mathrm{GFAP}^{-/-} \mathrm{Vim}^{-/-}$reactive astrocytes was clearly different
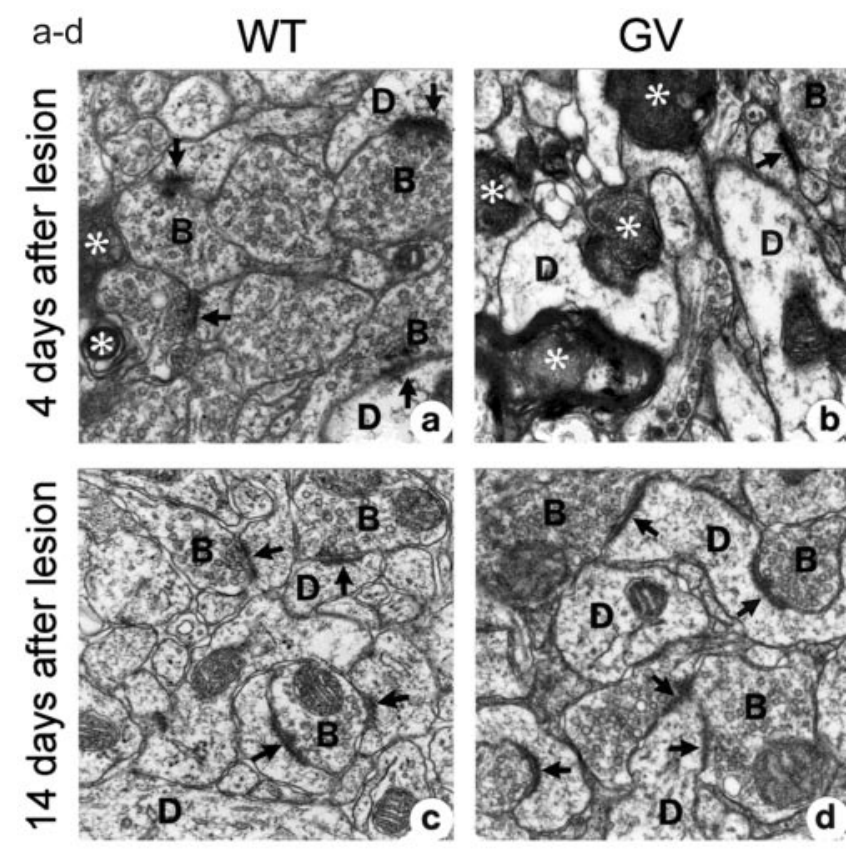

e

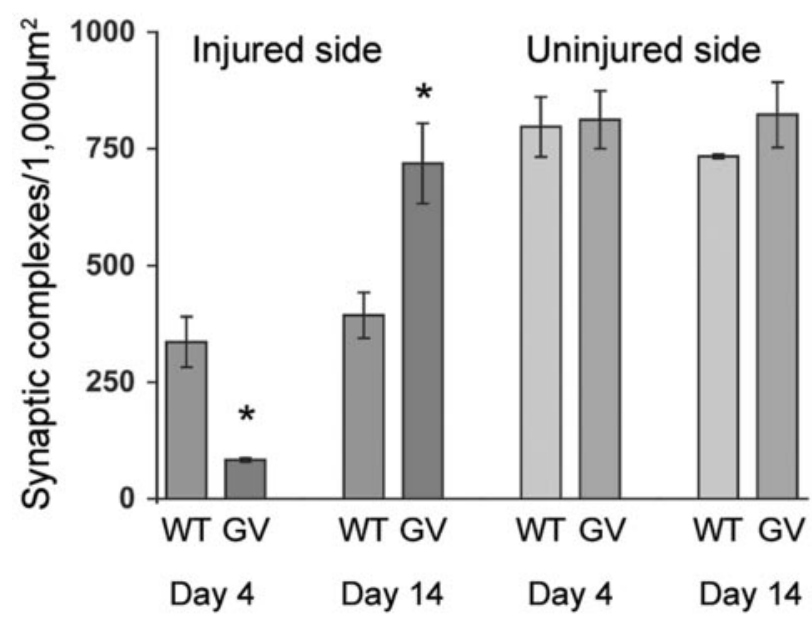

Figure 3. Complete synaptic restoration in $G F A P^{-/-} \mathrm{Vim}^{-/-}$(GV) mice by day 14 after entorhinal cortex lesion. Electron microscopy of the outer molecular layer of the dentate gyrus of the hippocampus 4 and $14 \mathrm{~d}$ after entorhinal cortex lesion is shown. $a, b$, Compared with wild-type (WT) mice (a), GFAP ${ }^{-1-} \operatorname{Vim}^{-1-}$ mice $(b)$ had a greater number of degenerated axons $\left({ }^{*}\right)$ and fewer synaptic complexes (arrows) by day 4.c, $d$, Ten days later, GV mice exhibited a remarkable recovery $(d)$, and the number of synaptic complexes in the outer molecular layer exceeded that in WT mice (c). D, Dendritic profile; B, synaptic bouton. Quantification of synaptic complexes in the outer molecular layer of the dentate gyrus of the hippocampus showed that $\mathrm{GV}$ mice had one-fourth as many synaptic complexes as WT mice by day $4\left({ }^{*} p<0.05\right)$. By day 14 , GV mice had twice as many synaptic complexes as WT mice ( $\left.{ }^{*} p<0.05\right)$. e, Between days 4 and 14 , the number of synaptic complexes increased $11 \%$ in WT mice and $77 \%$ in GV mice.

from wild type (Fig. $2 g$ ). GFAP ${ }^{-/-} \mathrm{Vim}^{-/-}$reactive astrocytes had $37 \%$ fewer processes that extended over a $20 \mu \mathrm{m}$ radius $(p<$ 0.0001 ) (Fig. $2 e, h$ ) as well as $83 \%$ fewer processes that remained straight for most of their length $(p<0.0001)$ (Fig. $2 f, h)$. Thus, the absence of intermediate filaments does not affect the volume of tissue accessed by reactive astrocytes but alters their morphology.

To assess the extent of synaptic loss and regeneration after entorhinal cortex lesion, we quantified synaptic complexes in the outer molecular layer of the dentate gyrus of the hippocampus by electron microscopy. Compared with wild-type mice, GFAP ${ }^{-/-}$ $\mathrm{Vim}^{-1-}$ mice had a greater loss of synaptic complexes and more 
abundant signs of axonal degeneration on the lesioned side by day 4 (Fig. $3 a, b$ ). Indeed, on the injured side, GFAP ${ }^{-/-}$ $\mathrm{Vim}^{-1-}$ mice had only one-fourth as many synaptic complexes in the outer molecular layer as wild-type mice $(p<0.05)$ (Fig. $3 e)$. The number of synaptic complexes was decreased to $10 \%$ in $G F A P^{-/-}$ $\mathrm{Vim}^{-1-}$ mice and to $43 \%$ in wild-type mice, compared with the respective contralateral side. These findings indicate that the absence of astrocytic intermediate filaments exacerbates the loss of synaptic complexes early after entorhinal cortex lesion. Between days 4 and 14, the number of synaptic complexes in the outer molecular layer of the dentate gyrus of the hippocampus on the lesioned side increased by $11 \%$ in wild-type mice (Fig. $3 e$ ), consistent with findings in rats (Matthews et al., 1976; Steward et al., 1983). Strikingly, the number of synaptic complexes in GFAP ${ }^{-/-}$ $\mathrm{Vim}^{-1-}$ mice increased by $77 \%$, reaching the levels measured on the contralateral side, and essentially all signs of axonal degeneration disappeared (Fig. $3 c, d$ ).

The upregulation of endothelin $\mathrm{B}$ receptors by astrocytes in the injured CNS was proposed to be one of the steps leading to astrocyte activation and hypertrophy (Ishikawa et al., 1997; Baba, 1998; Koyama et al., 1999; Peters et al., 2003). By using Ab against endothelin $\mathrm{B}$ receptors, we found weak and almost exclusively endothelial immunostaining in the molecular layer of the dentate gyrus of the hippocampus on the side contralateral to entorhinal cortex lesion, fully comparable in wild-type and GFAP ${ }^{-/-}$Vim $^{-/-}$mice (Fig. 4a,b). As expected, on the lesioned side at both 4 and $14 \mathrm{~d}$ after entorhinal cortex lesion, endothelin B receptors were highly upregulated on reactive astrocytes in wild-type mice (Fig. 4c) (data not shown). However, no signs of endothelin $\mathrm{B}$ receptor upregulation were found on astrocytes of GFAP ${ }^{-/-}$Vim $^{-/-}$mice (Fig. 4d) (data not shown). Thus, the upregulation of endothelin $\mathrm{B}$ receptors on reactive astrocytes is intermediate filament dependent.

\section{Discussion}

We show here that in the absence of astrocytic intermediate filaments, the cellular processes of reactive astrocytes failed to exhibit their characteristic hypertrophy. This was associated with a fourfold greater loss of neuronal synapses than in wild-type mice by day 4 after entorhinal cortex lesion. These findings demonstrate that reactive astrocytes play a beneficial role in the acute stage after CNS injury and suggest that hypertrophy of astrocytic processes associated with astrocyte activation is of major functional significance.

Most surprisingly, within a few days after entorhinal cortex lesion, the reactive astrocytes began to pose an obstacle to regeneration. This conclusion is based on the observation that between days 4 and 14, the number of neuronal synapses in $G F A P^{-/-} \mathrm{Vim}^{-/-}$ mice was restored to preinjury levels. Ultrastructurally, the new synapses were indistinguishable from those in uninjured mice and could be formed either by axonal sprouting of existing neurons or
WT

GV

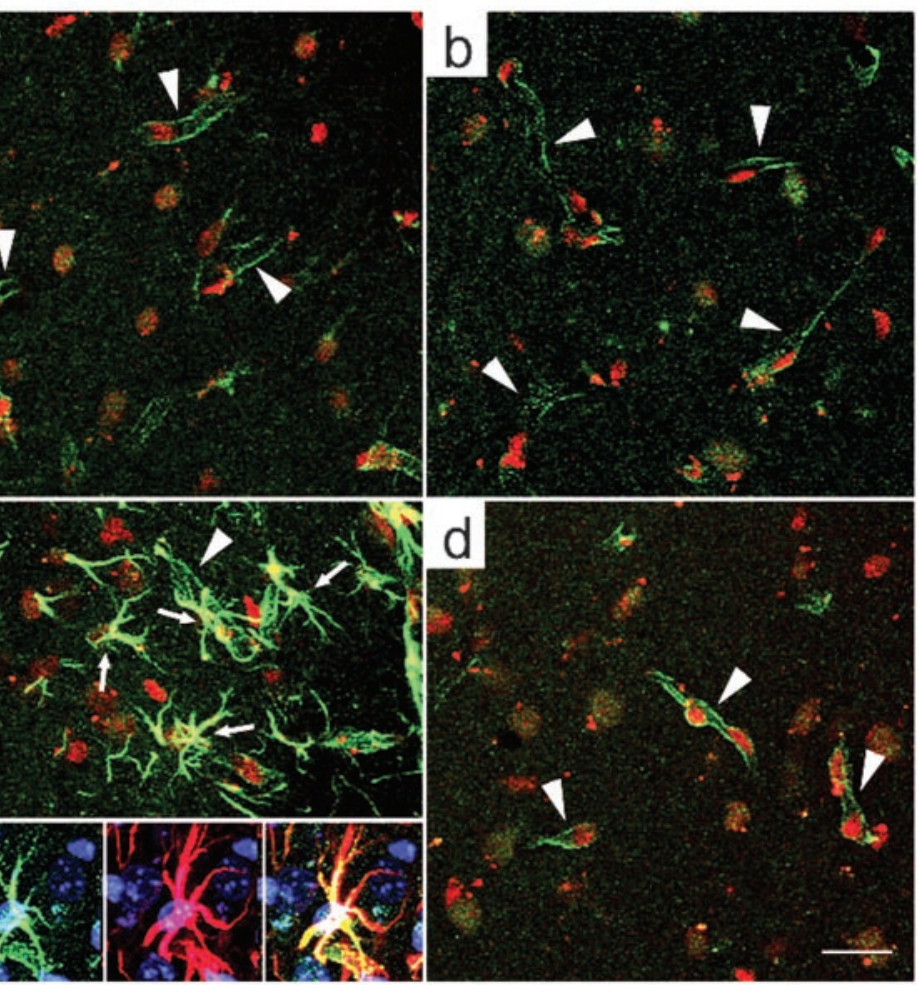

Figure 4. Endothelin B receptors are not upregulated on $G F A P^{-/-} \mathrm{Vim}^{-1-}$ reactive astrocytes. Before entorhinal cortex (ans) in WT mice; essentilly allendothelin B receptor-positiveastrocytes are upregulation was seen on reactive astrocytes in GV mice. $a-d$, Green, Endothelin B receptors; red, cell nuclei visualized by propidium iodide. Inset, Green, Endothelin B receptors; red, GFAP; blue, cell nuclei visualized by TO PRO-3. Scale bar, $20 \mu \mathrm{m}$.

by differentiation of neurons generated from neural precursor cells.

The increased regeneration after CNS trauma in the GFAP ${ }^{-/-}$ $\mathrm{Vim}^{-/-}$mice appears to result from the reduced hypertrophy of cellular processes of individual reactive astrocytes. Even though $G F A P^{-1-} \operatorname{Vim}^{-1-}$ and wild-type reactive astrocytes reach the same volume of brain tissue, hypotrophic processes of $\mathrm{GFAP}^{-/-} \mathrm{Vim}^{-/-}$ astrocytes might not allow the same degree of control within this volume. We propose that reduction of this "functional action radius," and thus of the area the astrocytes can effectively control, lifts the inhibition on CNS regeneration. Thus, the hypertrophy of processes of reactive astrocytes appears to be of fundamental importance in inhibiting CNS regeneration. This functional action radius scenario would explain the relative lack of neuroprotection in $\mathrm{GFAP}^{-/-} \mathrm{Vim}^{-/-}$mice at an early post-traumatic stage, when astrocytes throughout the affected region may be required for spatial buffering, neurotransmitter removal, or reconstruction of the damaged blood-brain barrier. It may also explain the impaired post-traumatic glial scarring in $G F A P^{-/-}$ Vim $^{-1-}$ mice (Pekny et al., 1999) as well as the improved integration of neural transplants into the CNS of $\mathrm{GFAP}^{-1-} \mathrm{Vim}^{-/-}$mice (Kinouchi et al., 2003).

Do $G F A P^{-1-} \operatorname{Vim}^{-1-}$-reactive astrocytes differ from wild-type also on a molecular level? Hypertrophy of astrocytic processes in response to CNS trauma is normally accompanied by upregulation of endothelin B receptors (Ishikawa et al., 1997; Baba, 1998; Koyama et al., 1999; Peters et al., 2003). Moreover, it was suggested that 
blockage of endothelin B receptors may attenuate the formation of astrocytic glial scar (Rogers et al., 2003), which does not fully develop in $G F A P^{-1-}$ Vim $^{-1-}$ mice (Pekny et al., 1999). Here, we show that upregulation of endothelin $\mathrm{B}$ receptors by reactive astrocytes requires an intermediate filament network, and that the absence of endothelin B receptor upregulation in astrocytes is associated with improved post-traumatic regeneration.

Are there other molecules differentially expressed by wildtype and GFAP ${ }^{-1-}$ Vim $^{-1-}$ astrocytes? The number of candidates with a potentially modulatory effect on CNS regeneration remains to be examined (e.g., chondroitin-sulfate proteoglycans produced by reactive astrocytes). These extracellular matrix proteins form lattice-like structures around neurons, known as perineuronal nets, and were demonstrated to hinder plasticity in the visual cortex (Pizzorusso et al., 2002).

Apart from implicating astrocytes as potent inhibitors of CNS regeneration, our findings provide new information about intermediate filaments, which also can be valid for other cell types. As demonstrated first for keratins in epithelial cells, and subsequently for other intermediate filament proteins, the function of intermediate filaments is primarily to increase the mechanical resistance of cells and tissues (McLean and Lane, 1995; Fuchs and Cleveland, 1998). In the absence of any challenge, the lack of intermediate filaments in astrocytes does not have any major consequences (Gomi et al., 1995; Pekny et al., 1995, 1999), perhaps because other components of the cytoskeleton, such as actin filaments, can compensate and provide the support necessary for the development and maintenance of processes of nonreactive astrocytes. However, when the structural demands imposed on a cell are increased, as in reactive astrocytes that undergo hypertrophy of cellular processes, the intermediate filaments become indispensable, and compensatory mechanisms are no longer effective. Thus, intermediate filaments should perhaps be viewed primarily as subcellular structures of fundamental importance in stress, when a maximal cellular response is required to avert an imminent threat.

\section{References}

Baba A (1998) Role of endothelin B receptor signals in reactive astrocytes. Life Sci 62:1711-1715.

Berthold CH, Corneliuson O, Rydmark M (1982) Changes in shape and size of cat spinal root myelinated nerve fibers during fixation and Vestopal-W embedding for electron microscopy. J Ultrastruct Res 80:23-41.

Bush TG, Puvanachandra N, Horner CH, Polito A, Ostenfeld T, Svendsen CN, Mucke L, Johnson MH, Sofroniew MV (1999) Leukocyte infiltration, neuronal degeneration, and neurite outgrowth after ablation of scarforming, reactive astrocytes in adult transgenic mice. Neuron 23:297-308.

Bushong EA, Martone ME, Jones YZ, Ellisman MH (2002) Protoplasmic astrocytes in CA1 stratum radiatum occupy separate anatomical domains. J Neurosci 22:183-192.

Bushong EA, Martone ME, Ellisman MH (2003) Examination of the relationship between astrocyte morphology and laminar boundaries in the molecular layer of adult dentate gyrus. J Comp Neurol 462:241-251.

Caceres A, Steward O (1983) Dendritic reorganization in the denervated dentate gyrus of the rat following entorhinal cortex lesions: a golgi and electron microscopic analysis. J Comp Neurol 214:387-403.

Chen MS, Huber AB, van der Haar ME, Frank M, Schnell L, Spillmann AA, Christ F, Schwab ME (2000) Nogo-A is a myelin-associated neurite outgrowth inhibitor and an antigen for monoclonal antibody IN-1. Nature 403:434-439.

Colucci-Guyon E, Portier MM, Dunia I, Paulin D, Pournin S, Babinet C (1994) Mice lacking vimentin develop and reproduce without an obvious phenotype. Cell 79:679-694.

Delaney CL, Brenner M, Messing A (1996) Conditional ablation of cerebellar astrocytes in postnatal transgenic mice. J Neurosci 16:6908-6918.

Eliasson C, Sahlgren C, Berthold CH, Stakeberg J, Celis JE, Betsholtz C, Eriksson JE, Pekny M (1999) Intermediate filament protein partnership in astrocytes. J Biol Chem 274:3996-4006.
Fournier AE, GrandPre T, Strittmatter SM (2001) Identification of a receptor mediating Nogo-66 inhibition of axonal regeneration. Nature 409:341-346.

Fuchs E, Cleveland DW (1998) A structural scaffolding of intermediate filaments in health and disease. Science 279:514-519.

Gomi H, Yokoyama T, Fujimoto K, Ikeda T, Katoh A, Itoh T, Itohara S (1995) Mice devoid of the glial fibrillary acidic protein develop normally and are susceptible to scrapie prions. Neuron 14:29-41.

GrandPre T, Nakamura F, Vartanian T, Strittmatter SM (2000) Identification of the Nogo inhibitor of axon regeneration as a Reticulon protein. Nature 403:439-444.

Harlow E, Lane D (1988) Antibodies: a laboratory manual, p 418. Cold Spring Harbor, NY: Cold Spring Harbor Laboratory.

Ishikawa N, Takemura M, Koyama Y, Shigenaga Y, Okada T, Baba A (1997) Endothelins promote the activation of astrocytes in rat neostriatum through ET(B) receptors. Eur J Neurosci 9:895-901.

Kinouchi R, Takeda M, Yang L, Wilhelmsson U, Lundkvist A, Pekny M, Chen DF (2003) Robust neural integration from retinal transplants in mice deficient in GFAP and vimentin. Nat Neurosci 6:863-868.

Koyama Y, Takemura M, Fujiki K, Ishikawa N, Shigenaga Y, Baba A (1999) BQ788, an endothelin ET(B) receptor antagonist, attenuates stab wound injury-induced reactive astrocytes in rat brain. Glia 26:268-271.

Matthews DA, Cotman C, Lynch G (1976) An electron microscopic study of lesion-induced synaptogenesis in the dentate gyrus of the adult rat. II. Reappearance of morphologically normal synaptic contacts. Brain Res 115:23-41.

McLean WH, Lane EB (1995) Intermediate filaments in disease. Curr Opin Cell Biol 7:118-125.

Nishida A, Takahashi M, Tanihara H, Nakano I, Takahashi JB, Mizoguchi A, Ide C, Honda Y (2000) Incorporation and differentiation of hippocampus-derived neural stem cells transplanted in injured adult rat retina. Invest Ophthalmol Vis Sci 41:4268-4274.

Ogata K, Kosaka T (2002) Structural and quantitative analysis of astrocytes in the mouse hippocampus. Neuroscience 113:221-233.

Pekny M (2001) Astrocytic intermediate filaments: lessons from GFAP and vimentin knock-out mice. Prog Brain Res 132:23-30.

Pekny M, Leveen P, Pekna M, Eliasson C, Berthold CH, Westermark B, Betsholtz C (1995) Mice lacking glial fibrillary acidic protein display astrocytes devoid of intermediate filaments but develop and reproduce normally. EMBO J 14:1590-1598.

Pekny M, Eliasson C, Chien CL, Kindblom LG, Liem R, Hamberger A, Betsholtz C (1998) GFAP-deficient astrocytes are capable of stellation in vitro when cocultured with neurons and exhibit a reduced amount of intermediate filaments and an increased cell saturation density. Exp Cell Res 239:332-343.

Pekny M, Johansson CB, Eliasson C, Stakeberg J, Wallen A, Perlmann T, Lendahl U, Betsholtz C, Berthold CH, Frisen J (1999) Abnormal reaction to central nervous system injury in mice lacking glial fibrillary acidic protein and vimentin. J Cell Biol 145:503-514.

Peters CM, Rogers SD, Pomonis JD, Egnazyck GF, Keyser CP, Schmidt JA, Ghilardi JR, Maggio JE, Mantyh PW (2003) Endothelin receptor expression in the normal and injured spinal cord: potential involvement in injury-induced ischemia and gliosis. Exp Neurol 180:1-13.

Pizzorusso T, Medini P, Berardi N, Chierzi S, Fawcett JW, Maffei L (2002) Reactivation of ocular dominance plasticity in the adult visual cortex. Science 298:1248-1251.

Richardson KC, Jarett L, Finke EH (1969) Embedding in epoxy resins for ultrathin sectioning in electron microscopy. Stain Technol 35:313-323.

Ridet JL, Privat A, Malhotra SK, Gage FH (1997) Reactive astrocytes: cellular and molecular cues to biological function. Trends Neurosci 12:570-577.

Rogers SD, Peters CM, Pomonis JD, Hagiwara H, Ghilardi JR, Mantyh PW (2003) Endothelin B receptors are expressed by astrocytes and regulate astrocyte hypertrophy in the normal and injured CNS. Glia 41:180-190.

Silver J, Miller JH (2004) Regeneration beyond the glial scar. Nat Rev Neurosci 5:146-156.

Steward O, Vinsant S (1983) The process of reinnervation of the dentate gyrus of the adult rat: an analysis of terminal proliferation and reactive synaptogenesis. J Comp Neurol 214:370-386.

Stone DJ, Rozovsky I, Morgan TE, Anderson CP, Finch CE (1998) Increased synaptic sprouting in response to estrogen via and apolipoprotein E-dependent mechanism: implications for AD. J Neurosci 18:3180-3185. 